\title{
ARTICLE
}

\section{Psychosexual history-taking in the 21st century: new terminology, new technology and new risks}

\author{
Lisa Gardiner
}

Lisa Gardiner, $\mathrm{MB}, \mathrm{BCH}, \mathrm{BaO}$, MRCPsych, is a consultant forensic psychiatrist and psychotherapist working in Ravenswood House Medium Secure Unit in Hampshire, UK. She is training programme director for forensic psychiatry in the Wessex School of Psychiatry. Correspondence Dr Lisa Gardiner Ravenswood House, Mayles Lane, Knowle, Fareham P017 5NA, UK. Email: lisa.gardiner3@nhs.net

\section{Copyright and usage}

(C) The Royal College of Psychiatrists 2018

\begin{abstract}
SUMMARY
Sexual and relationships difficulties are not uncommon among psychiatric patients. A presenting complaint of anxiety or depression may relate to an underlying sexual or relationship difficulty; commonly used psychotropic medications cause sexual side-effects that can have a significant impact quality of life, relationship maintenance and treatment adherence; patients may exhibit unusual or excessive sexual behaviours when acutely unwell, including risky use of apps to meet sexual partners and accessing online pornography in unsafe ways; patients may have used technology such as the internet to harm others or they may be victims of such harm; the internet and social media might even be influencing sexual expression, for example gender identity. Therefore, psychosexual history-taking remains a key competency for psychiatrists. They must also understand the new language used to describe sexuality, sexual behaviours and the use of social media, apps and so on to form relationships. This article outlines the key areas to consider in carrying out a structured psychosexual assessment. It also gives an overview of current sexual terminology, observed influences of the internet on sexuality and sexual behaviour, and its implications for mental health and potential sexual offending.
\end{abstract}

\section{LEARNING OBJECTIVES}

After reading this article you will be able to:

- outline a framework for psychosexual historytaking

- recognise emerging terminology relating to sexual behaviours and identity

- understand the relevance of the internet, social media and technology-based apps to human relationships, including the use of technology in sexual offending

\section{DECLARATION OF INTEREST}

None.

\section{KEYWORDS}

Education and training; sexual and gender identity disorders; forensic mental health services.
Taking a full psychiatric history when carrying out the initial assessment of a patient should include taking a psychosexual history (Downey 2009). In clinical practice, this may be limited to inquiring about past and present relationships and the experience of trauma such as childhood sexual abuse. This limitation may be due to time pressures during the assessment interview. Other factors that may affect taking a thorough psychosexual history include: clinician embarrassment; a wish to avoid embarrassing the patient and/or affecting the nascent therapeutic relationship; focus on the presenting problem(s); and a lack of training and experience in taking a psychosexual history (Crawford 1998; Rele 2007; Balon 2010).

Yet as the 21st century progresses, taking a psychosexual history appears more, not less, important. Referrals to gender identity services such as the Tavistock Clinic in London have increased dramatically in the past 10 years (Kaltiala-Heino 2015; Lyons 2016; Joseph 2017). Anxiety, depression and selfharm rates among adolescents continue to rise, with cyber-bullying identified as a factor. Cyber-bullying is an adverse experience that may include pressure to share explicit sexual images, as well as non-consensual sharing of explicit images, among peer groups, on social media or on the internet (Temple2012; Korenis 2014; Rafla 2014; Van Geel 2014).

Information and communications technology (technology, for short) has become an important means of finding relationships and sexual partners, with internet dating now the acceptable face of a spectrum of technology that includes apps to find local sexual partners by 'swiping' left or right on Tinder or Grindr (Holloway 2014; Klettke 2014). Terms such as 'sexting', 'ghosting', 'stealthing' and 'catfishing' have entered everyday language; and courtship may include sending or receiving 'dick pics’ (Thompson 2016; Connelly 2017; Wilson 2017) (see Box 1 for definitions of these terms).

Likewise, sexual offending increasingly involves use of the internet and social media: with rates of arrests and charges for viewing images of child sexual abuse having increased by $48 \%$ in England and Wales between 2007 and 2011 (Cafe 2013). 
There is as yet little consensus on how non-contact offending (such as viewing explicit images) relates to progression to contact sexual offences (McManus 2014; Babchishin 2015). Individuals may come to the attention of the courts if they procure and watch the abuse of a child or adult in remote countries via the internet (Holmes 2016).

\section{Psychosexual history-taking in general psychiatric settings}

How and when elicits a psychosexual history is elicited is dependent on the nature and purpose of the assessment interview. In a general psychiatric clinic, the assessing psychiatrist may wish to spend the first meeting eliciting the patient's presenting complaint and building rapport, with the intent of assessing the psychosexual history at a later date. In contrast, in a psychosexual medicine assessment clinic, the focus may rest entirely on taking a detailed psychosexual history over the course of one or more sessions. In many psychiatric settings, a thorough personal history may cover all psychosexual history that relates to the presentation and the management of the psychiatric disorder.

Any psychiatrist must consider a number of factors before meeting with a patient to take a psychosexual history. The gender of the psychiatrist and of the patient should be considered. Some patients may wish to speak about sexual matters to someone of their own gender; some will prefer to speak to someone of the opposite gender. If a patient has experienced sexual abuse, what was the gender of the abuser? What was their relationship? It can affect a patient adversely if they have to recount sexual material to a professional figure who resembles an abusive parental figure, regardless of the actual personal and professional qualities of the psychiatrist involved.

Psychiatrists' professional status gifts them such power and authority that it behoves them to be mindful of the real imbalances of power in every doctor-patient relationship. These imbalances become more powerful when patients are in a situation that, by its nature, makes them more vulnerable, strips away some of the ordinary social conventions and may evoke feelings in either party that are both powerful and uncomfortable - such as disgust, anger, sadness and covert (or overt) excitement, including sexual arousal, which may be involuntary. In these clinical situations, psychiatrists must be capable of remaining in touch with their feelings and reflecting internally on their emotional reactions to the patient and his or her material. This must be a process that prioritises the patient's well-being and safety.

This must also be a process that gives some measure of control to the patient. For example, the

\section{BOX 121 st-century sexual terminology}

Sexting: sending and/or receiving sexually explicit messages and/or indecent images via text messaging/instant messaging services such as IM+, WhatsApp and Snapchat

Dick pics: explicit images of one's erect penis sent (often unsolicited) to a potential partner via text, instant messaging or email; dick pics may also be used in harassment or bullying of a victim

Catfishing: posing under a false identity online to lure someone into a relationship (which may be sexual, friendship or fraudulent)

Ghosting: the practice of suddenly ending a relationship by stopping all communication

Stealthing: the practice of covertly removing a condom during sexual activity without the partner's knowledge or consent

Chemsex: intentional sex, sometimes with multiple partners, while using illegal drugs to enhance sexual performance and sexual enjoyment; most common among men who have sex with men, but also seen among heterosexuals

Gender fluid: an individual who does not identify as having a fixed gender identity and moves between gender roles
Gender non-binary: someone who rejects a strictly 'masculine' or 'feminine' gender identity but identifies with aspects of both genders

Cis gender: a term used by the transgender community to indicate an individual who identifies as their biological sex (also referred to as 'natal' or 'assigned' gender)

Preferred pronoun: it is good practice to ask someone who identifies as non-binary, gender fluid or transgender what their preferred name and pronoun are

Asexual: someone who does not feel sexual attraction to either gender and has little interest in sex

Incel: a contraction of 'involuntarily celibate'; the term was originally coined as an inclusive identity, but has been adopted by particular online communities (mainly of men) who endorse or carry out acts of harm against sexually active people

This list is far from comprehensive. For further reading on LBOT identities and terms, please access a website such as Stonewall (e.g. http://www.stonewall.org.uk/help-advice/ glossary-terms) psychiatrist should be explicit at the outset that the patient can and should take breaks as needed, take their time and feel confident that they can choose to stop the history-taking at any point without feeling they would be penalised or in some way disappointing to the doctor. This sounds much easier than it sometimes is and the doctor must remain attuned to the patient's experience during the historytaking process and proactively offer pauses, breaks and checks on the patient's well-being.

Another consideration may be the patient's religious or cultural background. Again, the gender of the assessing doctor needs to be sensitively addressed with the patient. Even with a doctor of the same gender, it may be helpful to consider whether a chaperone is necessary and appropriate and who can fulfil this role. Unfortunately, it may also be necessary to consider whether someone attending with the patient is someone who is not offering support but is there to police or control the patient's narrative. For this reason, careful thought should be given to who is performing the chaperone role.

If an interpreter is needed, this should always be a professional interpreter with mental health experience, not a partner or family member - partly 
because of the issue raised above but also because of factors such as simple confidentiality and the ability to accurately translate complex medical and psychiatric terms that even doctors can struggle to put into simple language.

Being able to develop the clinical skills of asking about sexual matters in a sensitive, matter-of-fact manner is one of the key techniques to taking a history about things that many people find difficult or embarrassing to discuss. For some clinicians, a lack of confidence in their psychosexual historytaking skills and/or anxiety about the potential for embarrassment can hinder enquiries into such a sensitive area. Furthermore, the patient may be aware that the assessing psychiatrist is embarrassed and may be adversely affected as a result, for example the clinician's embarrassment may be perceived as a reason to feel shame.

Being able to acknowledge with a patient that these are difficult questions, to offer reassurance that they are doing well and to offer taking a break or coming back to something later are all likely to be appreciated by patients. It is important to use clear, simple language and err on the side of being blunt, as using euphemisms may confuse doctor and patient alike. If a patient does not wish to talk about a subject, the clinician should accept this and move on.

The clinician must be guided by the patient's cues. Being able to pick up on non-verbal cues is useful, but the patient's need for privacy in such sensitive matters must be respected throughout. For example, some patients will be very distressed by disclosing trauma and may exhibit symptoms such as dissociation; some will be desperate to tell their stories and will feel relieved by the process of disclosure.

In covering this area with patients who have a significant history of trauma such as sexual abuse, it can be easy to slip into a doctor-patient relationship that ends up replaying the dynamics of the patient's relationship with their abuser. In such a case, it may be best to take a step back and consider why the psychosexual history is being elicited in the current circumstances and whether it is necessary. If it is (for example) limited enquiry about sexual side-effects of medication, should this lead on to a detailed history including experience of abuse? If it is for a purpose known to you and to the patient (such as a psychotherapy referral for the treatment of psychological difficulties stemming from sexual abuse), it might be wiser and kinder to set some time aside with the patient first to consider how to go about covering the material in a way that the patient finds manageable.

Given that talking about sexual difficulties is something with which most people struggle, the patient may only hint at sexual concerns or mention them only in the closing minutes of the interview. It is easy to share the patient's discomfort and collude in failing to gather important information.

Psychiatrists working with younger people in particular may encounter patients who have been traumatised as a result of exposure to pornography or who are suffering because of a partner's expectation that they engage in sexual acts normalised by pornography - such as being choked ('breath play') or engaging in coercive anal sex (Marston 2014). This may be particularly marked for young adults, who may have poor self-boundaries and unclear ideas about healthy sexual consent (Wolak 2007; Owens 2012), and enquiry about risk-taking sexual behaviour may be an invaluable part of the overall psychiatric assessment.

While learning these skills, trainees need access to an experienced and trusted supervisor with expertise in this area, who can help them to refine their historytaking skills and to process the emotional responses to this clinical work. Similarly, access to a case-based discussion group (CBDG) can help trainees understand their emotional responses to clinical material encountered when taking a psychosexual history. Attendance at CBDGs for a minimum of 1 year is a mandatory part of core psychiatric training in the UK.

\section{Psychosexual history - background material}

\section{Presenting complaint}

The presenting complaint may be fairly straightforward. For example, if a patient with schizophrenia presents with new onset of erectile dysfunction, a brief psychosexual history should help identify whether the dysfunction is related to the sideeffects of antipsychotic medication or a problem such as relationship stress.

\section{Family history}

It may be wise to draw out a genogram during the consultation. Some families are formed of complex relationship networks and, where names are shared across generations, it can be difficult to unpick who did what when and to whom without a clear diagram to refer to later in the consultation.

\section{Personal history}

\section{Childhood}

Childhood history should ideally include details of the patient's neurodevelopment. This may show the presence of an autism spectrum disorder or intellectual disability. These disorders can have a significant influence on how the family treats the individual, including their vulnerability to sexual exploitation. Prolonged enuresis and encopresis can be signifiers of emotional, physical and sexual abuse (Kellogg 2005). Relationships inside and outside the family 
are important, especially if the patient or other family members have experienced abuse or neglect. Does the patient report experiences of emotional, physical or sexual abuse and neglect? If so, has this been previously disclosed and what was the outcome of disclosure? Are there ongoing safeguarding issues? It is important that clinicians are aware of their own responsibilities should a disclosure indicate that other children or vulnerable adults remain at risk of harm, and they must keep up to date with local safeguarding policies and good practice.

\section{Schooling and employment}

Enquiry about schooling allows for exploration of issues that would suggest autism spectrum disorder or intellectual disability, as well as evidence of behavioural disturbance or conduct disorder in adolescence. Exploring experiences of bullying may include experience of cyber-bullying such as sexual victimisation or exploitation and grooming via social media. An employment history may uncover disruption or disciplinary problems related to sexual misconduct at work, such as accessing pornography on work computers or compulsive masturbation disrupting work performance (Griffiths 2003).

\section{Romantic/sexual relationships}

A romantic/sexual relationship history may encompass the patient's sexual orientation, their history of relationships (e.g. duration, quality of relationship, resulting children, abusive experiences, how the relationship ended) and current relationship status without going into any detail on sexual experiences and practices. In most cases, this is perfectly acceptable and has little bearing on the assessment of their mental health or on managing any mental disorder. Asking about matters such as domestic violence or child protection issues is likely to be of greater importance than documenting the age at which a patient first had sex.

\section{Psychiatric history}

Individuals with mental disorders may have significant psychosexual difficulties related to the illness, the treatment of the illness (including psychosocial consequences such as institutionalisation) and/or problems associated with the illness, including stigma. A recent review of the literature showed that up to $70 \%$ of women with schizophrenia reported sexual dysfunction and only $13 \%$ of people with schizophrenia maintained a steady relationship (Montejo 2018). Sexual difficulties can, of course, pre-date the onset of mental illness (Marques 2012), so it is important not to assume that any psychosexual difficulty relates only to a comorbid mental disorder or medication - patients are not solely their illnesses!

It is important that clinicians who prescribe for and monitor patients with mental disorders do not forget that sexual health is a component of both physical and mental health. Between 50 and $73 \%$ of patients with psychosis report poor history-taking regarding their sexual well-being (Montejo 2010). In addition, some people with mental health problems engage in more sexually risky behaviours, whether due to factors related to the illness (such as active symptoms of mania), vulnerability to exploitation or abuse (for example, intellectual disability or prominent negative symptoms of schizophrenia), or for reasons unrelated to their mental illness (Carey 2001).

Therefore, psychiatrists should consider making some level of routine enquiry about patients' sexual health and well-being. This includes asking about experience of sexual side-effects with medications known to cause problems directly (such as selective serotonin reuptake inhibitors, SSRIs) or indirectly (antipsychotics through prolactin rise) and the impact of symptoms on sexual function in relationships, for example a depressed patient's lack of libido may have a significant effect on a partner's well-being. Where a medication is causing significant sexual side-effects, consideration should be given to alternative drugs (for example, switching from risperidone to aripiprazole may improve sexual function).

Patients take medications that necessitate concomitant use of contraceptives (such as women taking sodium valproate) should have access to proper counselling about this, as well as support should they wish to start a family.

Neurodevelopmental disorders may also affect the individual's sexuality - for example, higher rates of asexuality are reported by individuals with autism spectrum disorder (Gilmour 2012) and higher rates of autism spectrum disorder are seen in adolescent girls presenting to gender identity clinics (KaltialaHeino 2015). Relationships may be more difficult for individuals with autism spectrum disorder, owing to difficulties in reading social cues and vulnerability to abuse and exploitation. Individuals with intellectual disability may face similar problems, as well as struggling with stigma, especially if they have an obvious chromosomal abnormality such as Down syndrome. Adults with an intellectual disability should be supported to access the same standard of services for sexual health, including suitable contraception advice, as any other adult.

\section{Structured psychosexual history - when a more detailed approach is required}

A structured history-taking schedule can be helpful when learning history-taking skills; as an 
aide-mémoire during a longer or more complex assessment; and as a means of managing the anxieties arising from asking about sexual experiences and behaviours. Use of a structured psychosexual history may be particularly helpful at the outset of psychiatric training, to familiarise trainees with the breadth of the domains under inquiry. However, it can be difficult to find out how to take a detailed psychosexual history, as many commonly used psychiatry textbooks and handbooks give only limited details on eliciting this information that do not extend far beyond taking a detailed personal history. This can add to the perception that this is a difficult and shameful area of inquiry for a psychiatrist to undertake, rather than an assessment of an innate part of human experience that changes and evolves during the life-cycle.

Another advantage of using a structured list of questions is that it can (especially in the early stages of the assessment) be used to put the patient at ease during what may be experienced as an intrusive and voyeuristic process where the assessor is bombarding them with prurient questions. For trainees in particular, being able to apologise for the nature of the questions while explaining that these are the questions on the form used by the clinic, can turn such an assessment from an exposing and persecutory experience for the patient into a mutual task to be completed. The question list can also be helpful in identifying what the individual patient will talk about in a comfortable manner and what areas raise anxiety and tension, indicating that more careful exploration may be needed.

However, a structured approach to history-taking that is based on a list of questions or criteria should not prevent the assessor using open questions to elicit the information required. The aim should always be, if possible, to elicit the patient's narrative of their sexual development and experiences. This narrative will sit in the context of their overall life and relationship experiences, which may encompass the full spectrum from significant trauma and abuse to joy and fulfilment brought about by romantic and non-romantic relationships.

Other situations in which a structured approach may be useful include assessments in psychosexual medicine clinics and the assessment of patients with a history of sexual offending, either as part of a risk assessment or to prepare a court report in criminal proceedings. In these circumstances, more information is needed for the assessment process and if the time allowed for the interview is limited it is useful to consider carrying out the assessment over a number of interview sessions.

\section{How to take a structured psychosexual history}

A structured psychosexual history assessment should cover seven areas, which we outline in this section (we discuss assessment of sex offenders in a separate section):
1 sexual development
2 physical development
3 gender identity and sexual orientation
4 sexual history
5 masturbation history
6 hypersexuality
7 presence of sexual disorders.

The lists of questions to explore in each area are intended to help make explicit the breadth and detail of information to be considered. As an assessor gains experience and confidence in their skills in psychosexual history-taking, one would expect a gradual shift towards being able to gather the relevant information using open questions from the outset of the interview.

\section{Sexual development}

This can be divided into the patient's emotional development and the process of learning about sex. Areas to explore include:

- how the patient found out about sex

- attitudes to sex in the home (puritanical or open; how sex was talked about; attitudes to sexual material on television)

- exposure to pornography - age at first exposure, who was the exposure provided by, media type, porn type, response (trauma, arousal, precursor to sexual activity or abuse) (Box 2)

- use of pornography as an adolescent; responses and/or habits

- exposure to parental sexual activity

- experiences of sexual abuse and/or exploitation

- experiences of acting as a sexual abuser before adulthood.

\section{Physical development}

The clinician should ask about the person's physical development, looking for abnormal or traumatic experiences or experiences that have caused distress. Areas to consider include:

- age at puberty

- whether the individual was prepared for puberty (e.g. sex education at school; parental talks about sex; books or material to prepare for puberty; provision and explanation of items such as sanitary protection) 
BOX 2 Childhood exposure to pornography

Rates of exposure to pornography during childhood are rising. A paper published in 2005 referenced a study reporting that $90 \%$ of 8 - to 16 -year-olds had viewed pornography online, usually when completing homework (Quinn 2005). It is unclear whether this was accidental exposure. This paper pre-dates the widespread use of tablet computers by very young children: a recent Mumsnet survey (Internet Watch Foundation 2018) reported that 16\% of carers of children under 4 years of age and $28 \%$ of carers of 4- to 6-year-olds said the child they look after had used online video streaming without adult supervision - including the use of video streaming sites such as YouTube, or using live-chat functions provided by the game, console or an app to talk to other users while playing.

- experience of puberty

- age at first menarche for female patients

- age at first wet dream and first erection for male patients

- age at first masturbation and masturbatory habits

- for female patients, and as appropriate to the patient's age: history of menstruation, pregnancy, abortion/miscarriage/stillbirth, childbirth and menopause, along with experience of associated physical and/or psychological symptoms such as premenstrual syndrome, ante- or post-natal depression.

\section{Gender identity and sexual orientation}

The assumption of this article is that the presenting complaint is not gender dysphoria and that the patient is not wishing to initiate the process of gender transition. However, a patient may report confusion about sexual identity and/or orientation as part of a condition such as emotionally unstable personality disorder or autism spectrum disorder (World Health Organization 1992; Kaltiala-Heino 2015). In such cases, it is reasonable to expect the clinician to be capable of taking a basic history of the patient's narrative about their gender identity across their lifetime.

If the patient has gender dysphoria or presents as gender non-conforming or gender non-binary (Box 1) in their social interactions it is also important that the assessing doctor checks the patient's preference regarding their name, gender identity and pronouns to be used in any clinical encounter. This may be something that is evident from the outset or something deeply private to the individual, but it should engender the same politeness and respect a doctor offers any patient.

Complications may arise if a patient has (legally or otherwise) changed their name and/or gender from the name and sex indicated in their medical records and is unhappy that records remain under their original name and biological sex. In the UK, National Health Service trust and board policies can vary widely on what to do in such instances. It is usually (but not always) acceptable for the clinician to advise the patient that they will record the interaction using the individual's current preferred name and identity within the clinical record, possibly with an introductory note advising colleagues how to address the patient during future interactions.

\section{Sexual history}

As can be seen from the list below, a sexual history can encompass a very wide area indeed. However, it should be tailored to fit the patient. It might be appropriate to consider the biological sex and presented gender as part of the reason for the assessment. In assessing a patient complaining of loss of libido occurring after starting an SSRI, it might be appropriate to focus only on sexual habits. For a homosexual male presenting in a manic state, it may be dangerous not to ask about risky sexual behaviours such as participating in chemsex with multiple partners (Box 1). The risks associated with chemsex arise both from the practising of unsafe sex - for example, sexually transmitted infections (STIs), sexual assault and rape, physical assault and robbery - and from the drugs taken, which include methamphetamine (crystal meth) and $\gamma$-hydroxybutyrate (GHB) (McCall 2015).

Depending on the patient being assessed, areas of enquiry include:

- age at first sexual experiences and loss of virginity

- understanding of consent

- sexual habits: frequency, regularity, who with, types of sexual behaviour engaged in (including their repertoire of penetrative and non-penetrative sex, use of sex aids, unusual behaviours)

- risk-taking during sex: for example, not using condoms, stealthing (Box 1), multiple partners, sexual activity with strangers (including those met using apps such as Tinder or Grindr), drug use and/or intoxication with alcohol during sex

- any experience of harm arising from sexual activity: STI, unwanted pregnancy, sexual assault or rape, violence experienced from a sexual partner, coercive sex during a controlling or violent relationship

- pattern of use of services offered by sex workers

- evidence of paraphilias affecting sex with a partner or involved in sexual activity (Box 3) and how the paraphilia has affected current and past relationships

- sadomasochistic behaviours

- non-consensual and violent sexual behaviours 
BOX 3 Paraphilias

Unusual sexual interests/fantasies/behaviours outlined in ICD-10 (F65):

- fetish objects (non-human objects and body parts)

- sadomasochism, bondage and domination

- paedophilia

- necrophilia

- bestiality/zoophilia

- voyeurism

- exhibitionism

- frotteurism or uninvited touching

- obscene telephone calls

- internet pornography 'addiction'

- transvestitism, especially fetishistic

- involving urination and excretion

(World Health Organization 1992)

- sexual behaviours that are specific to the age and orientation of the patient: for example, older gay men in urban areas may have engaged in 'cottaging' (going to particular public or semi-public place to engage in sexual activity, such as public toilets or parkland).

\section{Masturbation history}

Asking about masturbatory fantasies and habits is a part of the history-taking that always raises anticipatory anxiety for both doctor and patient. However, it may be a source of very valuable information about a patient's internal world, especially in comparison to their real-world relationships and sexual habits. Areas to consider include:

- masturbatory habits: frequency, regularity, use of sexual aids, unusual behaviours during masturbation (e.g. autoerotic asphyxiation)

- masturbatory fantasies: description of commonly used fantasies, range of fantasies (flexible or stereotyped, violent, paraphilic or involving risk to self or others, including children?)

- use of pornography: type, source, frequency of use in masturbation

- inappropriate masturbation: at work or in public, evidence of excessive urges, urges cannot be resisted, etc.

As use of technology continues to influence human sexual behaviour, any subtype of pornography is now readily accessible online and often free. It is likely that rates of referral to clinics for 'porn addiction' or compulsive masturbation relating to ease of access to pornography will continue to increase, as is already being reported in the media (Blunden 2018).
Therefore, when asking about use of pornography it would be appropriate to ask about use of the internet to access it.

With widespread use of smartphones and tablets, alongside wireless internet (wi-fi) coverage across much of the UK, people can and do access pornography in settings once unthinkable - for example, watching explicit sexual videos on public transport. Likewise, where once one may have had to put significant effort into accessing 'hardcore' or niche pornography (e.g. going to expensive, strenuous and risky efforts such as travelling outside the UK to obtain it and smuggling it back into the country), now one can simply type terms into a search engine or access specialist 'adult' sites or even the Dark Web using an anonymising browser.

\section{Hypersexuality}

Hypersexuality may be a manifestation of several psychiatric or neurological disorders, such as mania or brain injury. It may occur as a side-effect of medication to treat Parkinson's disease. It is important to assess for the presence of hypersexuality during the assessment of sex offenders, as it may guide as to whether medication is offered to manage sexual arousal. The symptoms of hypersexuality are listed below, although only one component may be present:

- excessive urges and behaviours

- impulsivity

- ruminations and obsessive thoughts on sex and urges

- compulsive sexual behaviours.

\section{Presence of sexual disorders}

Diagnosable sexual disorders in men and women as identified in ICD-10 are listed Box 4.

\section{Sexual offending: history-taking and related matters}

How to take a history regarding sexual offending depends on whether one is assessing a defendant before trial or a convicted sex offender after sentencing. There are particular implications for the former, as any report may be produced in criminal court and therefore is not confidential. Areas to cover include:

- sexual abuse of children: contact and non-contact offending; lone offending; offending with a codefendant or as part of a wider abuse network; relationship to victim; grooming behaviours (which can encompass a range of means to access victims); incest

- making and/or distributing child sexual abuse images 
BOX 4 Sexual disorders

Female sexual disorders

- Failure of sexual desire/interest

- Pain experienced in the vulva and vagina (vulvodynia)

- Painful spasm of vaginal muscles that may prevent or occur on penetration (vaginismus)

- Painful sexual intercourse (dyspareunia)

- Excessive sexual urges

- Failure of orgasm (anorgasmia)

Male sexual disorders

- Failure of sexual desire/interest

- Difficulties with getting and/or maintaining an erection (erectile dysfunction)

- Reaching a climax too early (premature ejaculation)

- Other problems with ejaculation (such as failed or retrograde ejaculation)

- Difficulties with orgasm

- Painful sexual intercourse

- sexual assault: non-penetrative/penetrative

- rape and attempted rape

- violence towards sexual partners for own gratification

- acquisitive crime with a focus on obtaining sexual gratification, for example stealing underwear or a fetish item

- stalking behaviour with a sexual focus

- sexually motivated harassment, which may include use of technology - telephone calls, text messages, instant messaging, social media, emails, internet sites, etc.

- involvement in sexual offences such as voyeurism and exhibitionism; again, these may include use of technology - for example, recording exhibitionistic behaviour using a telephone and/or uploading these recordings to social media or the internet; note that such behaviours may or may not be illegal depending on local legislation.

As mentioned above, it is worth performing an assessment around hyper-sexuality during the assessment of sex offenders. This is relevant when considering the prescription of medication to manage sexual arousal (MMSA). For example, individuals with features such as excessive rumination on sexual material may respond to treatment with an SSRI (Garcia 2013).

\section{Legal consequences of sexual offending}

Individuals convicted of sexual offences may require assessment for mental health problems and it may be useful to know some of the potential criminal penalties or restrictions imposed by the criminal justice system. These will vary by jurisdiction and the terminology below relates to England and Wales. Areas to cover include:

- prison sentence or community sentence; involvement of probation and any licence conditions; other restrictions, such as being placed on the sex offender register or imposition of a sexual offences prevention order by the court (this allows the criminal justice system agencies to monitor the offender's use of technology or to prohibit its use)

- access to and completion of a sex offender treatment programme

- use of medication to manage sexual arousal and response to treatment

- compliance with supervision and licence/other legal conditions.

\section{Additional consequences of sexual offending}

Individuals may suffer other consequences of sexual offending, including negative effects on relationships, access to their children, home or local area, impacts on employment and a raised profile in local or national media. This may lead to mental health difficulties requiring psychiatric input. For example, sexual offences against pupils by teachers are commonly of interest to the national press and this publicity can cause offenders (or even alleged offenders) to develop suicidal thoughts and impulses that may bring them into contact with mental health services.

Some individuals who have convictions for sexual offending manage to maintain relationships or employment. Although it is not the psychiatrist's professional duty to make moral judgements on such matters, it is vital to be aware of proper safeguarding processes for children and vulnerable adults and to follow these correctly.

\section{Technology and sexuality}

One way of classifying technology-related sexual behaviours, suggested by Quinn \& Forsyth (2005), is an adaptation of the classification of sexually deviant behaviours. This classification uses three categories: normal, pathological and sociological. 'Normal' deviance relates to acts that may be felt to be publicly unacceptable but are commonly practised in private; 'pathological' deviance relates to acts that are illegal or considered harmful, so that few members of society engage in them; 'sociological' deviance describes behaviours that require the formation of a social network to support them - for example, anything from naturism, to swinging (partner swapping) to paedophile networks. Quinn $\&$ Forsyth suggest subdividing the sociological category to include a category relating to the role of technology, while also recognising technology's 
importance in the normal and pathological deviance categories.

Technology influences sexuality and sexual behaviour in many ways. The internet is important in attracting previously uninterested people who may be curious or seek stimulation; it can act as a 'safety-valve', a space that can be used to express fantasies and so avoid acting on harmful behaviours; it can support the development of subcultures endorsing acts outside social norms. It has also enabled the creation of internet-based markets for illegal activities and the channels for sharing of information, including the evasion of arrest (Stalans 2016).

Another perspective on technology's influence on sexuality comes from the concept of 'social contagion' - the spread of an idea or activity through a community or population. A first description of social contagion appeared after the publication in 1774 of Goethe's novel The Sorrows of the Young Werther (in which the protagonist kills himself), which was said by some to have been followed by a spate of suicides across Europe (Phillips 1974). Social contagion continues to be recognised as important in suicide prevention, and with the widespread use of the internet it has been found to be influential in increasing rates of eating disorders in adolescent girls and has been put forward as a potential factor in the increase in rates of presentation of adolescent girls to gender identity services (Marchiano 2017; Midgen 2018).

For adolescents, the internet offers a range of arenas in which to explore an emergent adult identity, from social media platforms such as Instagram, to specific websites promoting certain identities as desirable (for example, 'pro-ana' websites for anorexia nervosa), to chatrooms, to videostreaming sites where individuals wishing to explore different ways of presenting gender identity can watch how-to guides on breast-binding or 'packing' underwear to resemble male genitals. It is relevant that the adolescent girls presenting to gender identity services in a Finnish study (Kaltiala-Heino 2015) included a significant subgroup of very isolated teenagers (49\%), who reported persistent experiences of bullying before the onset of gender dysphoria. It is likely that internet use may be higher in socially isolated individuals, increasing their vulnerability to contagion by access to websites that promote ways to change identity and can offer much wished-for validation and support by other members of the subgroup.

\section{Behaviours involving the use of technology in sexuality}

It is still too early to say what impact social networking will have on how humans relate to each other, but we have been quick to adapt to every change and advance in technology not just for the purposes of friendship but also to make romantic and sexual connections.

SMS text messaging has introduced the possibility of 'sexting' (sending sexually explicit messages via text message), while the cameras now built into mobile phones allow individuals to take explicit pictures and/or videos of themselves (or others) that can be sent by text or instant messaging services, emails and mobile phone apps or uploaded to the internet.

Although such images may be made and shared between consenting adults without incident, problems arise when explicit images are sent unsolicited or to someone not consenting to receive such material. While most adults will not be adversely affected by receiving an unsolicited explicit image, some recipients find such material upsetting or traumatising. Sending explicit and unsolicited images to a victim may also form part of harassment behaviours. In other cases, material (e.g. explicit images or videos) made while part of a couple either with or without the other person's knowledge and consent is used, usually after the couple breaks up, to intimidate that person with threats of sharing the images. In some cases, the subject only becomes aware of the sharing or distribution of images after they have been posted to internet pornography websites.

The situation becomes more complex when it comes to younger adults, adolescents and children. Explicit images may be taken by the subject or with the subject's knowledge and consent and sent to a romantic interest but the individuals taking the images may be under the legal age of consent. Leaving aside the increasingly recognised problem of the use of such images in bullying and cyberbullying, taking, sharing and possessing sexually explicit images of children under 18 years of age is an offence within the UK. While the Crown Prosecution Service in England and Wales does not generally support prosecution in cases where images have been shared between children of a similar age, it is still recorded as a crime. The guidance makes it clear that prosecutions may be sought where there is evidence of exploitation, grooming, profiting or malicious intent in making and sharing such images.

The situation is of course different for adults found to have made, distributed or been in possession of sexual images of children, or to have used social media to engage in grooming behaviours towards individuals under 18 years of age. This applies not only to 'real' images of children but also to manufactured or computer-generated sexually explicit imagery involving children.

In each of these very different situations, psychiatrists play a secondary role to other services, such as 
the police or safeguarding agencies. However, psychiatrists may play an important role after the fact, for example in assessing children who have been cyber-bullied and who are distressed and selfharming, or if instructed by the courts to prepare a psychiatric report on a defendant charged with possession of indecent images of children.

At the time of writing, legislators are attempting to keep pace with the misuses of technology to sexually harass, intimidate, bully or otherwise harm potential victims.

For example, 'upskirting' is the practice of illicitly taking photographs literally up the skirt (or dress) of an unwitting and unconsenting female victim. This act commonly takes place on public transport, given the cover afforded to perpetrators (men) by large crowds of people, the vulnerability of women using stairs or escalators, the ease of making an escape if an alarm is raised by the victim or a bystander, etc.

Upskirting has been illegal in Scotland since 2010, when it was added to a broadened definition of voyeurism offences under the Sexual Offences (Scotland) Act 2009. However, attempts to make it illegal in England and Wales in June 2018 as part of a private member's bill introduced in the House of Commons were blocked and, at time of writing, the UK Parliament intends to address the issue of 'upskirting' by introducing the Voyeurism (Offences) (No 2) Bill. This amends the offence of voyeurism to include upskirting. This has just had its second reading in the House of Lords on 23/10/18 (https://www.parliament.uk/business/ news/2018/october/lords-debates-voyeurism-offencesno-2-bill/) (BBC 2018).

One of the biggest challenges for psychiatrists is to keep up to date with technology and new terminology relating to sexual behaviour, identity and potential sexual offending. This is one area in which consultant and senior doctors may benefit from their junior colleagues' greater knowledge and understanding of modern technology and its uses.

\section{Conclusions}

Being able to take a competent psychosexual history is partly a matter of knowledge and partly a matter of practice. The prospect of performing a psychosexual assessement may give rise to feelings of anxiety in the inexperienced clinician, but this anxiety should be allayed by clinical experience. Not every patient presenting to psychiatric services will need as comprehensive a psychosexual history assessment as outlined in this article, but the structure described above may help to demystify the process of asking about such a sensitive but universal part of human experience.
Psychosexual difficulties and disorders may arise prior to mental health problems, during or as part of the treatment of common mental health difficulties and can be distressing to patients, as well as reducing their trust in professionals and adherence to treatment. Furthermore, if a patient gets the impression that the assessing psychiatrist does not understand the terminology that he or she uses when talking about him- or herself (or does not understand the importance of using the preferred pronoun for gender non-binary individuals), this will affect the clinician's ability to develop a good professional relationship and perform an accurate assessment of what the patient has presented with to clinic.

Finally, the rapid developments in technology during the second half of the 20th century and the early years of the 21st century have had a massive impact on human sexuality and relationships. The significance of such technological change cannot be overstated and its impact remains difficult to predict, particularly for the generations who have grown up with access to this technology. Given the importance of relationships to good mental health, it is essential that psychiatrists have an awareness and an understanding of this area and its potential influence on their patients.

\section{References}

Babchishin KM, Hanson RK, VanZuylen H (2015) Online child pornography offenders are different: a meta-analysis of the characteristics of online and offline sex offenders against children. Archives of Sexual Behavior, 44: 45-66

Balon R, Morreale M (2010) What has happened to teaching human sexuality in psychiatric training programs? Academic Psychiatry, 34: 325-7.

BBC (2018) Upskirting law to be passed soon, says Theresa May. BBC News Online, 16 June (https://www.bbc.co.uk/news/uk-politics-44504656).

Blunden $\mathrm{M}(2018)$ Number of Londoners seeking help for sex addiction soars. Evening Standard, 17 May (https://www.standard.co.uk/news/health/number-of-londoners-seeking-help-for-porn-addiction-soars-a3841541.html).

Cafe $\mathrm{R}$ (2013) Police detections of child porn images increases by $48 \%$. BBC News Online, 23 February (http://www.bbc.co.uk/news/uk-21507006).

Carey MP, Carey KB, Maisto SA, et al (2001) Prevalence and correlates of sexual activity and HIV-related risk behavior among psychiatric outpatients. Journal of Consulting and Clinical Psychology, 69: 846-50.

Connelly J (2017) 'Stealthing' - what you need to know. BBC Newsbeat, 25 April (http://www.bbc.co.uk/newsbeat/article/39705734/stealthingwhat-you-need-to-know).

Crawford MJ, Shaw T (1998) Psychiatric out-patients' views on talking about sex. Psychiatric Bulletin, 22: 365-7.

Downey JI, Friedman RC (2009) Taking a sexual history: the adult psychiatric patient. Focus, 7: 435-40.

Garcia FD, Delavenne HG, Assumpção ADFA, Thibaut F (2013) Pharmacologic treatment of sex offenders with paraphilic disorder. Current Psychiatry Reports, 15: 356.

Gilmour L, Schalomon PM, Smith V (2012) Sexuality in a community based sample of adults with autism spectrum disorder. Research in Autism Spectrum Disorders, 6: 313-8.

Griffiths M (2003) Internet abuse in the workplace: issues and concerns for employers and employment counselors. Journal of Employment Counseling, 40: 87-96.
MCO answers

1 c 2 b 3 e 4 b $5 c$ 
Holloway IW, Dunlap S, Del Pino HE, et al (2014) Online social networking, sexual risk and protective behaviors: considerations for clinicians and researchers. Current Addiction Reports, 1: 220-8.

Holmes 0 (2016) How child sexual abuse became a family business in the Philippines. Guardian, 31 May (https://www.theguardian.com/world/2016/ may/31/live-streaming-child-sex-abuse-family-business-philippines).

Internet Watch Foundation (2018) More parents worry about bad language online than about grooming or child sexual exploitation. Cambridge Network News, 20 July (https://www.cambridgenetwork.co. uk/news/parents-worry-bad-language-grooming-child-sexual-exploitation).

Joseph A, Cliffe C, Hillyard M, et al (2017) Gender identity and the management of the transgender patient: a guide for non-specialists. Journal of the Royal Society of Medicine, 110: 144-52.

Kaltiala-Heino R, Sumia M, Työläjärvi M, et al (2015) Two years of gender identity service for minors: overrepresentation of natal girls with severe problems in adolescent development. Child and Adolescent Psychiatry and Mental Health, 9: 9

Kellogg N (2005) The evaluation of sexual abuse in children. Pediatrics, 116: $506-12$

Klettke B, Hallford DJ, Mellor DJ (2014) Sexting prevalence and correlates: a systematic literature review. Clinical Psychology Review, 34: 44-53.

Korenis P, Billick SB (2014) Forensic implications: adolescent sexting and cyberbullying. Psychiatric Quarterly, 85: 97-101.

Lyons K (2016) Gender identity clinic services under strain as referral rates soar. Guardian, 10 July (https://www.theguardian.com/society/2016/jul/ 10/transgender-clinic-waiting-times-patient-numbers-soar-gender-identity-services)

Marchiano L (2017) Outbreak: on transgender teens and psychic epidemics. Psychological Perspectives, 60: 345-66.

Marques TR, Smith S, Bonaccorso S, et al (2012) Sexual dysfunction in people with prodromal or first-episode psychosis. British Journal of Psychiatry, 201: 131-6.

Marston C, Lewis R (2014) Anal heterosex among young people and implications for health promotion: a qualitative study in the UK. BMJ Open, 4 e004996.

McCall H, Adams N, Mason D, et al (2015) What is chemsex and why does it matter? BMJ, 351: h5790.

McManus MA, Almond L (2014) Trends of indecent images of children and child sexual offences between 2005/2006 and 2012/2013 within the United Kingdom. Journal of Sexual Aggression, 20: 142-55.

Midgen M (2018) Transgender children and young people: born in your own body. Journal of Child Psychotherapy, 44: 140-2.
Montejo AL, Majadas S, Rico-Villademoros F, et al (2010) Frequency of sexual dysfunction in patients with a psychotic disorder receiving antipsychotics. Journal of Sexual Medicine, 7: 3404-13.

Montejo AL, Montejo L, Baldwin DS (2018) The impact of severe mental disorders and psychotropic medications on sexual health and its implications for clinical management. World Psychiatry, 17: 3-11.

Owens EW, Behun RJ, Manning JC, et al (2012) The impact of internet pornography on adolescents: a review of the research. Sexual Addiction \& Compulsivity, 19: 99-122.

Phillips D (1974) The influence of suggestion on suicide: substantive and theoretical implications of the Werther effect. American Sociological Review, 39: 340-54.

Quinn JF, Forsyth CJ (2005) Describing sexual behavior in the era of the internet: a typology for empirical research. Deviant Behavior, 26: 191-207.

Rafla M, Carson NJ, DeJong SM (2014) Adolescents and the internet: what mental health clinicians need to know. Current Psychiatry Reports, 16(9): 1-10

Rele K, Wylie K (2007) Management of psychosexual and relationship problems in general mental health services by psychiatry trainees. International Journal of Clinical Practice, 61: 1701-4.

Stalans LJ, Finn MA (2016) Understanding how the internet facilitates crime and deviance. Victims \& Offenders, 11: 501-8.

Temple JR, Paul JA, van den Berg P, et al (2012) Teen sexting and its association with sexual behaviors. Archives of Pediatrics \& Adolescent Medicine, 166: 828-33.

Thompson $L$ (2016) Exposing yourself is illegal so why should the law tolerate cyber-flashing on online dating apps? The Independent, 4 February (http://www.independent.co.uk/life-style/love-sex/exposing-yourself-isillegal-so-why-do-online-dating-app-users-think-cyber-flashing-is-oka6852761.html).

Van Geel M, Vedder P, Tanilon J (2014) Relationship between peer victimization, cyberbullying, and suicide in children and adolescents: a meta-analysis. JAMA Pediatrics, 168: 435-42.

Wilson C (2017) Should 'catfishing' be made illegal? BBC News Online, 24 February (http://www.bbc.co.uk/news/uk-39078201).

Wolak J, Mitchell K, Finkelhor D (2007) Unwanted and wanted exposure to online pornography in a national sample of youth Internet users. Pediatrics, 119: 247-57

World Health Organization (1992) The ICD-10 Classification of Mental and Behavioural Disorders: Clinical Descriptions and Diagnostic Guidelines. WHO

\section{MCOs}

Select the single best option for each question stem

1 'Sexting' does not include:

a sending an explicit sexual image by text message

b attaching an indecent image of oneself to an email reply to an online dating partner

c posing under a false identity and engaging in a romantic relationship online

d sending a 'dick pic' when chatting to someone on Tinder

e describing explicit sexual acts via instant messaging to a sexual partner.

2 Hypersexuality does not include:

a impulsivity b gender dysphoria since early childhood

c compulsive sexual behaviours

$\mathrm{d}$ excessive urges and behaviours

e rumination and obsessive thoughts about sex.

3 A psychosexual history should include:

a history of brain injury

b history of depression

c symptoms of hypomania

d employment history

e all of the above.

4 Female sexual disorders include:

a vaginismus

b premature ejaculation c dyspareunia

d failure of sexual desire

e failure of orgasm.

5 Which of the following uses of technology is not generally considered a form of sexual offending:

a grooming via Facebook

b sharing indecent images of children through illegal file-sharing sites

c catfishing a prospective romantic partner

d procuring images of sexual offending against children in another country such as the Philippines

e sending indecent images repeatedly to someone who does not wish to receive contact from you. 